\title{
ヘリカルスキャンシステムにおけるMRヘッド用 薄層蒸着テープの検討 Investigation of thin metal evaporated tapes for MR head in helical scanning systems
}

\author{
小野持誠、若生仁志、传本哲雄、川名隆宏、池时義人*、尾末匡** \\ ソニ一(株) RMEカンバニ一マグネティックメディア開発部 \\ *CPCカンハニ一電子部品部、**中央研究所
}

\begin{abstract}
S.Onodera,H.Wako,T.Samoto,T.Kawana,Y.Ikeda*,T.Ozue**
Sony Corporation Recording Media \&Energy Company Magnetic Media R\&D Dept.

*CPC Company Electronic Components Dept. . **Research Center
\end{abstract}

\begin{abstract}
We investigated thin metal evaporated tapes with MR heads in a helical scanning system, trying to achive a high recording density. We found that ME tape can realize low $\mathrm{Mr} \cdot \mathrm{t}$ values by changing the amount of oxygen during evaporation and thickness of magnetic layer to obtain a low noise media. Thin ME tapes are suitable media for high sensitivity heads such as MR heads.
\end{abstract}

\section{1.はじめに}

ハードディスクシステムは高感度な MR(Magneto-Resistive)ヘッドが導入されてから面 記録密度、特にトラック密度を飛躍的に向上さ せてきた。我々はVTRやテー-プストリーマーと

して広く用いられているヘリカルスキャンシス テムに扔いて回転ドラムにMRヘッドを搭載し DLC(Diamond Like Carbon)保護膜付き蒸着テーブ との組み合わせでその高密度記録の可能性を確 恋した[1]。MRヘッドのような高感度なヘッド に必要な媒体の特性はMR素子を的和させない最 適な $\mathrm{Mr} ・ \mathrm{t}$ 値及び低ノイズ特性である。蒸着デー プは㖉布型テープに比べてその微細構造により 低ノイズ特性を示すことが確認されている [2][3]。ここではMRヘッドに適した媒体として 更に低ノイズの薄層蒸着テーブの検討を行なっ たので報告する。

\section{2.実験方法}

テープ䪦料の作製は真空斜力蒸着法を用いて 行なった。蒸着原料はコバルトを使用し、蒸着 中に酸素を導入しながら成膜している。背圧は

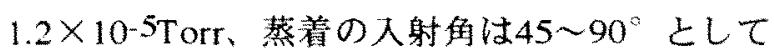
いる。膜厚の制御方法は蒸着中のテーブのライ ンスピードを変化させたり、電子ビームのパワ
一を変化させたり、入射角を変えたりして制御 できるが、今可はできるだけ磁気特性を変えな いて膜厚を制御できるようにラインスピードを 変えて成膜した。今回の実験に用いたMRへッ ドの諸元を表1に示す。SALバイアスのFeNi素 子を用い、その飽和磁化は800emu/cc，妻子と シールド間の距離を0.17 $\mu \mathrm{m}$ とし、トラック幅 は18 て測定した。また、組成解析はAES(Auger Electron Spectroscopy)、構造解析流高分解能 TEM(Transmission Electron Microscopy)を用いて 行なった。記録再生特性はドラムテスターを用 いて測定した。記録ヘッドはギャッブ長 $0.2 \mu \mathrm{m}$ のMIGヘッドを用い、相対速度は $3.5 \mathrm{~m} / \mathrm{s}$ で測定 した。

\section{3.結果と考察}

\section{3-1.最適Mrtの設計}

Co-CoO系蒸着テーブにおいて、媒体の残留 磁化Mrは蒸着中心道入する酸素量に依存する [4]。图 1に導入酸素量を変化させた時の膜厚

Table 1. MR head Specification

\section{SAL-biased FeNi-AMR}

Shield with NiZn-Ferrite

$\mathrm{Ms} \cdot \mathrm{t}$ of $\mathrm{MR}: 800 \mathrm{emu} / \mathrm{cc} \times 40 \mathrm{~nm}$

Shield to MR gap length : $0.17 \mu \mathrm{m}$

Longitudinal biasing : abutted structure

Track width : $18 \mu \mathrm{m}$

Azimuth Angle : 25 degrees 


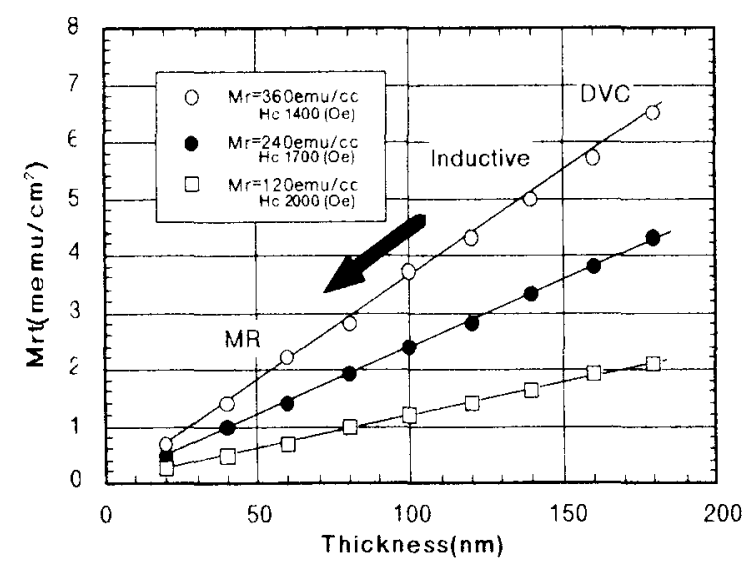

Fig.l $\mathrm{Mr} \cdot \mathrm{t} \quad$ values of Metal Evaporated Tapes

と $\mathrm{Mr} ・$ の関係を示す。膜厚及び導人酸素量を 変化することにより、 $\mathrm{Mr} \cdot 1$ の值を $1 \mathrm{mcmu} / \mathrm{cm}^{2}$ 以 下の領域まで容易に制御することができる。 DVC(Digital VideoCassette)などのInductive Head用 媒体のMr・蜏 $6 \mathrm{memu} / \mathrm{cm}^{2}$ の値となっている。 MR素子を線形動作させ、最大の再生出力を得る ためには媒体のMrとMR素子の飽和磁化Ms，膜 厚七との間に以下ような関係が必要である[5]。

$\mathrm{Mr}($ media $) \cdot \mathrm{t}($ media $)=0.4 \cdot \mathrm{Ms}(\mathrm{MR}) \cdot \mathrm{t}(\mathrm{MR})$

この条件で如何に媒体ノイズを低減できるかが 課題である。

また、磁性層の膜厚が薄くなることで、記録 されやすくなり最適記録電流も小さくなる。

図 2 にMrが360emu/ccのサン゙ルの記録波長0.5 $\mu \mathrm{m}$ における最適記録掣流を示す。また、薄層 化することで才-.-バーライト特性を收善する効 果も得られることも確認されている。

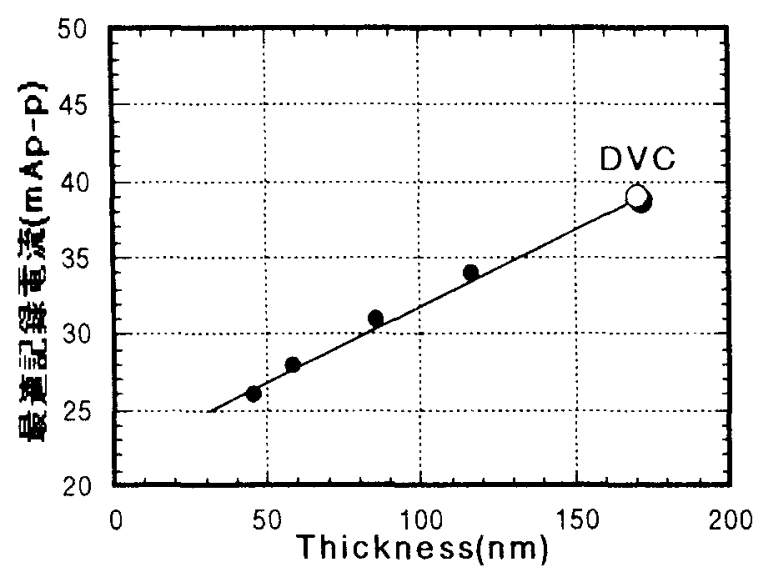

Fig.2 Dependence of optimum recording current on magnetick layer thickness

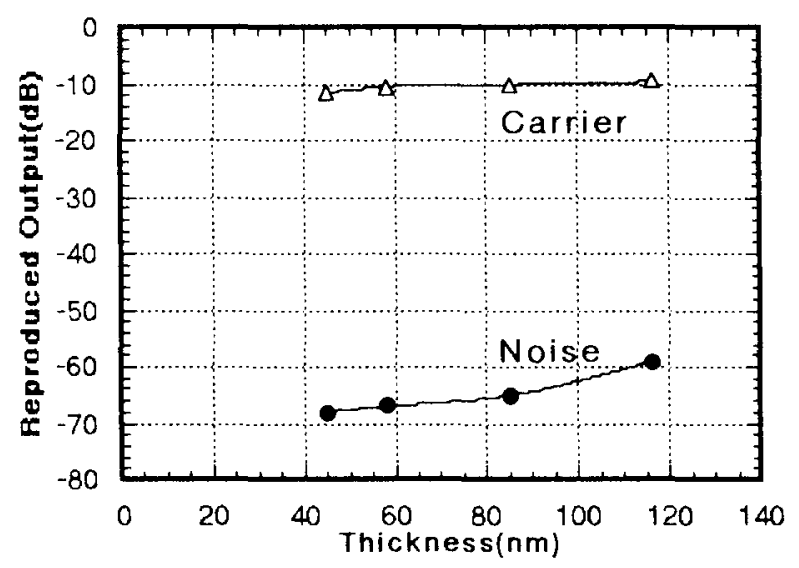

Fig.3 Thickness dependence of reproduced output and modulation noise level

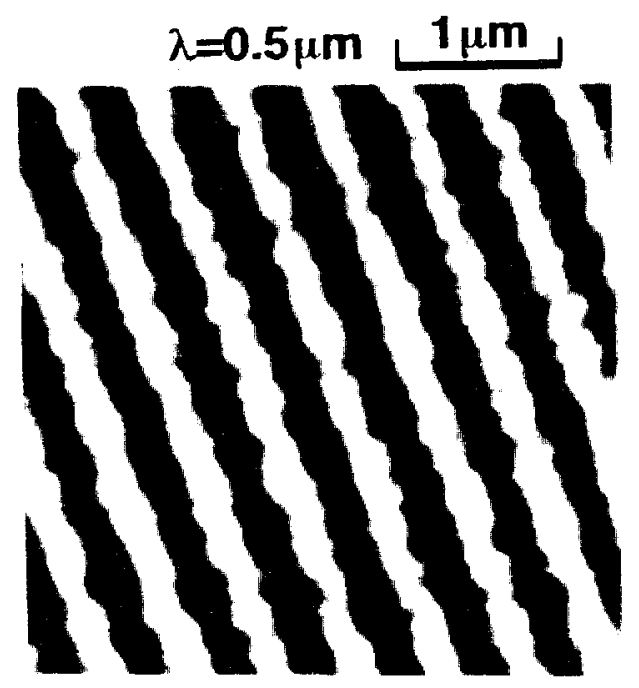

(a) $45 \mathrm{~nm}$

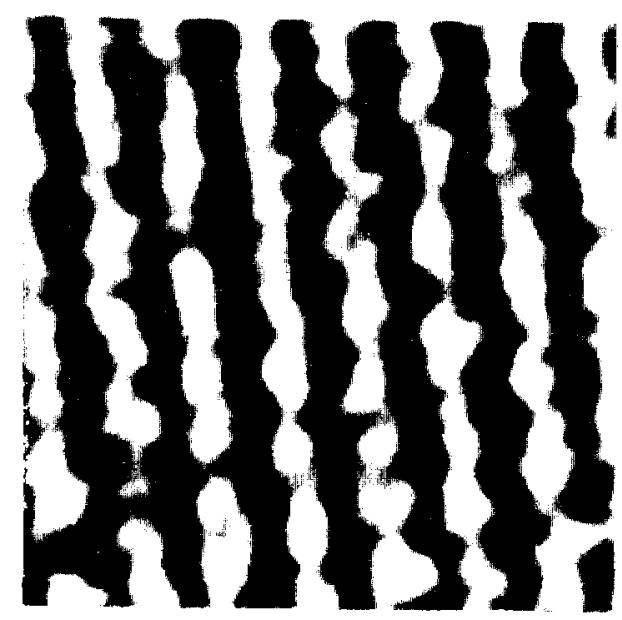

(b) $200 \mathrm{~nm}$

Fig.4 MFM images of each magnetic layer thickness 


\section{3-2.低ノイズ特性}

商感度なMRへッドを用いるためには媒体の低 ノイズ化は必須である。Co-O系蒸着テーブにお いて低ノイズ化を図るに流いくつかの力法があ る。‥つは磁性層膜厚を薄くすることである。図 3に磁性眉膜厚を変化させた時のスペクトラムア ナライザーで測定した再生信号と答調ノイズを示 ఫ. RBW ( Resolution Band Width) $=30 \mathrm{kHz}$, VBW(Video Band Width) $=10 \mathrm{kHz}$ ししたノイズレ ベル注信号から1MHz低い閭波数での值を示して いる。磁性曆膜厚を薄くなるほどノイズレベルが 低減していく。再生出力は約 $80 \mathrm{~nm}$ までは一定で あるが、それ以下の膜厚では徐々に低下する傾向 にある。膜厚が $40 \mathrm{~nm}$ に近づくと/イズの減少は 小さくなってくる。网4 に膜厚が $45 \mathrm{~nm}$ と200nm でのMFM像を示す。磁性層が薄くなることで、 遷移領域が明確になり、逆磁区も見られなくなっ ている。

媒体ノイズを低減する手段としては、道入酸素 量を增加させる力法がある[6]。酸素量を増加す ることで磁性粒子が微細化し保磁力が大きくなる ためと考えられる。图5に膜厚…定として酸素量 を変化させたときの変調ノイズと再生出力を示 す。酸素量が增加するにしたがってノイズレベル が減少していく。毒生出力は膜厚-...定のもとで酸 素舅を增加させていくと残留磁化が小さくなり減 少していく。更なる低ノイズ化を図るには磁性層 の多層化も有効である[7]。蒸着テーーブの磁性磨 最表面には非磁性の酸化䜺が形成されており、膜 曆方响の磁谷的結合を弱めるためである。

\section{3-4. 熱ゆらぎ}

また、Co-CoO系の蒸着テーブは非常に微紐な $\alpha$-CołよびCoO結晶粒子から成り立っているた め[8]、熱的な安定性について検討を行なった。 まずHigh resolution TEMの観察から $\alpha-\operatorname{CoO}$ 体積 分布を測定した結果を図6に示す。この物理的な 体積を用いてKu・V/kTを見積もるとその值は50 以下となり熱授らぎの影響を大きく受けてしまう 值となる。しかし、記録波長 $0.5 \mu \mathrm{m}$ での室温に おける再生浊力の経時変化を図 7 に亦すがその少 化は非常に小さく、安定している。そのため次に 媒体の活性化体積を求めた。摇らぎ場Hfは

$$
\mathrm{Hf}=\mathrm{S} / \chi \text { irr }
$$

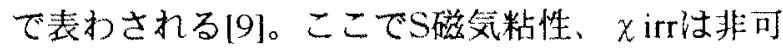
逆磁化率を表わす。また、摇らぎ場Hfより活性化 体積Vacを次式により求めることができる[10]。
$\mathrm{Vac}=\mathrm{kT} / \mathrm{MsHi}$

ここでkはボルツマン保数、Tは絶対温度、Msは 飽和磁化を表わす。これらの関係により求めた 活性化体積Vacの膜厚依任性を表 2 に示す。この 体積治前述の物理的な体積より大きくなつてい る。膜愿45から170nmにおいてHfおよびVacとも

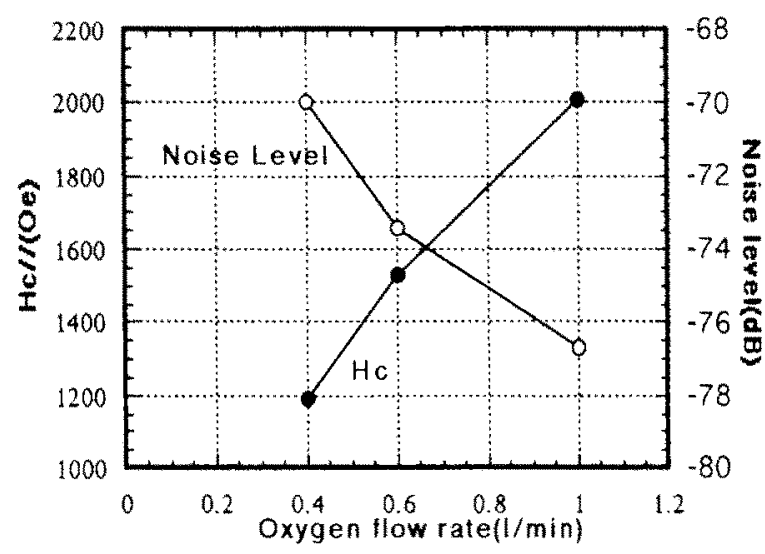

Fig.5 Dependence of modulation noise or oxygen flow rate

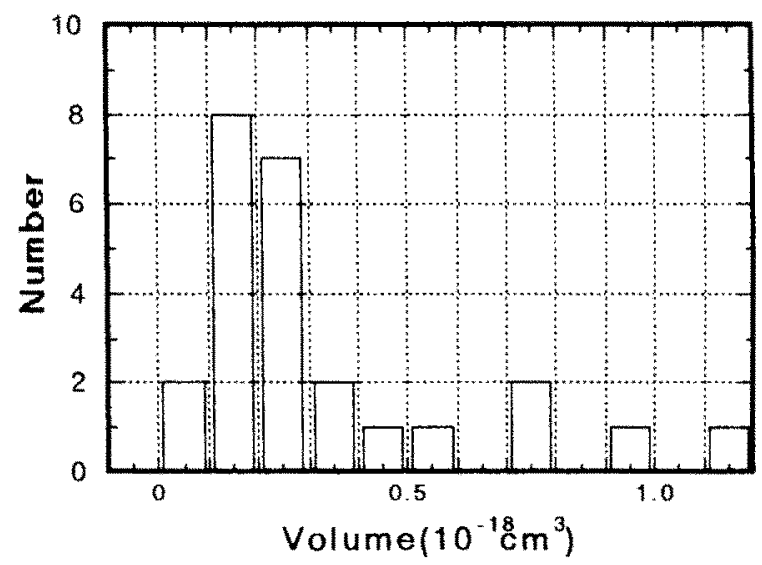

Fig.6 Volume distribution of $\alpha$-Co

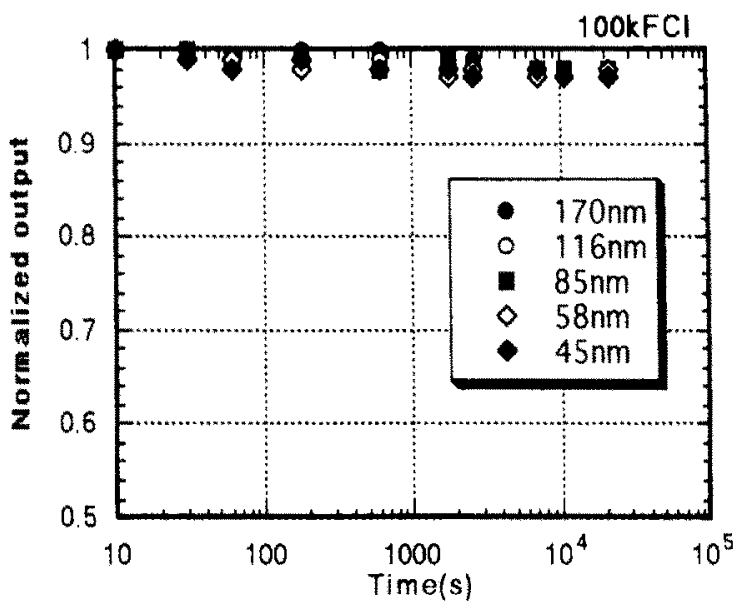

Fig. 7 Time dependence of normalized output for various thickness media 
Table 2 Thickness dependence of fluctuation field and activation volume

\begin{tabular}{ccc}
\hline Thickness(nm) & Hf(Oe) & $\operatorname{Vac}\left(10^{-18} \mathrm{~cm}^{3}\right)$ \\
\hline 170 & 10 & 8.0 \\
116 & 9 & 8.9 \\
85 & 10 & 8.5 \\
58 & 8 & 8.3 \\
45 & 11 & 8.0 \\
\hline
\end{tabular}

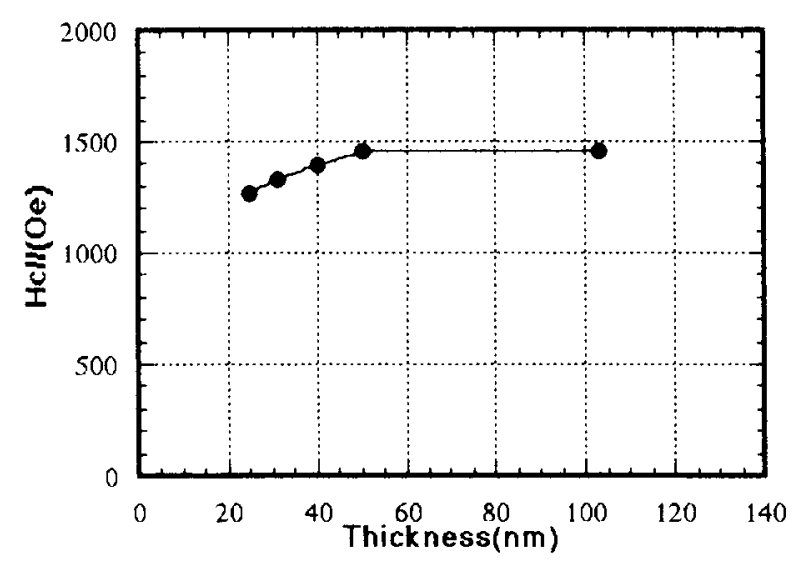

Fig.8 Thickness dependence of $\mathrm{Hc}$

ほとんど変化していないのがわかる。これは、 蒸着テ一フの微細粒子構造に起因していると考 えられる。 $\alpha-\operatorname{Co}$ の物理体積之磁気的な最小反転 体積が異なる理由、正確な物理体積の解析及 び、酸化度を高くした場合、より薄い媒体の熱 摇らぎの評価等が今後の課題である。

\section{3-4.下地効果}

更になる低ノイズ化を図るためにはより薄層 化を图り、また保磁力を向上しなければならな い。しかし、因8 亿示す様に膜厚が40nm以下の 領域になると保磁力が低下してくる。これを補 うために非磁性CO-O下地層が有効である[11]。磁 性層厚を50nm-定にすると、下地の膜厚が厚い ほど保磁力は问上するが $80 \mathrm{~nm}$ 程度で飽和する。 図9には下地の膜愿を80nmとし、下地の酸化度 の影響を調べた結果を示す。下地のみの保磁力 もあわせて示す。下地のみの場合、酸素量が $1.01 / \mathrm{min}$ 越えると急激に保磁力が低下し非磁性 に近づいてくる。このときの酸化度において、 磁性㸴を形成すると、2 倍近い保磁力が得られ る。

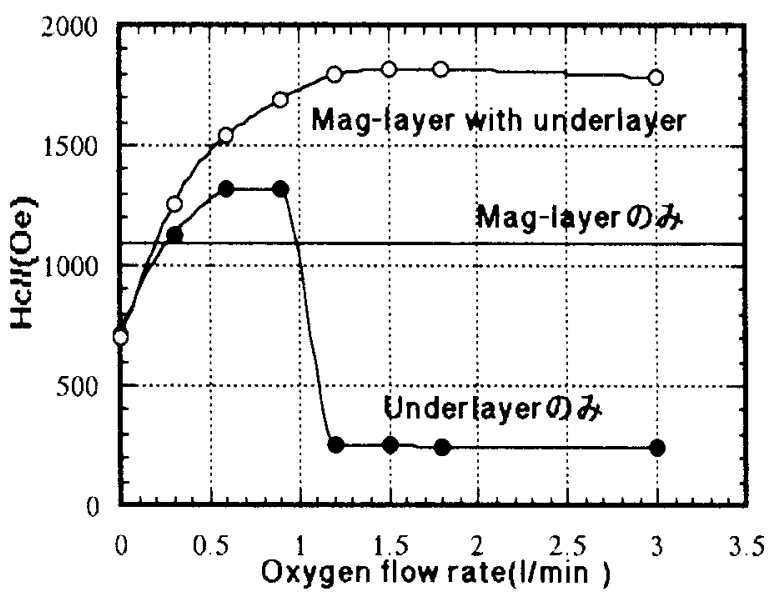

Fig.9 Dependence of $\mathrm{Hc}$ on underlayer oxidization

\section{4.まとめ}

ヘリカルスキャンシステムにおいてMRヘッド に対応した薄層蒸着テープの開発を行ない、MR ヘッドに適した低ノイズ媒体であることを確認 した。更に蒸着テーープは容易に媒体の Mr・tを制 御できる。また、今回用いたテープが45nm以上 の膜厚において熱摇らぎに対して問題のないこ ともわかった。更なる溥層化のために非磁性COOト地層の有効性も確認できた。

\section{5. 参考文献}

[1]T.Ozue,T.Shirai,T.Saito,T.Ikegami,H.Kano, and S.Onodera ,IEEE Trans. on Magn. Vol.34,No.4, 1492 (1998)

[2] K.Sato, K.Chiba, T.Ito, T.Sasaki and J.Hokkyo, J.Appl.Phys. vol.69,4736(1991)

[3]Y.Arisaka,K.Sato,Y.Yamada and K.Chiba, IEEE Trans. on Magn. Vol.MAG-27,4742(1991)

[4]蟻坂、佐藤、館野、飯田、千葉、佐々木：電 子情報通信学会春季全国大会、C-463,5-27(1990) [5]Bertram "Theory of Magnetic Recording" 191,Cambridge university press(1994) [6]J.Hokkyo,T.Suzuki,K.CHiba,Y.Arisaka,T.Sasaki and Y.Ebine,J.Magn. Magn.Mater. 120,281(1993)

[7]T.Kawana,S.Onodera and T.Samoto,IEEE Trans or Magn.Vol.31,No.6,2865(1995)

[8] 高山、棚橋、草田、矢野、小川：日本応用磁 気学会誌、19,NoS2,79(1995)

[9]P.Gaunt, J.Appl.Phys.vol.59,No.12,4129(1986)

[10] M.El.Hilo et.al.J.Magn.Magn.Mater.vol.

27,No.6,4666(1991)

[11]東間、杉田、吉本、不田：電子情報通信学会 技術研究報告MR98-85(1997) 